\title{
Spontaneous rupture of an epithelial cyst of the spleen
}

\author{
R. A. J. SPENCE* \\ F.R.C.S.
}

\author{
T. E. B. DANE \\ M.D., F.R.C.S.
}

Coleraine Hospital, Coleraine, Co. Londonderry, N. Ireland

\begin{abstract}
Summary
A case of spontaneous rupture of an epithelial cyst of the spleen which presented as an abdominal emergency is reported. Following splenectomy the patient made a complete recovery.
\end{abstract}

KEY WORDS: epithelial cyst, spleen, spontaneous rupture.

\section{Case report}

A 14-year-old boy was admitted with a four hour history of abdominal pain which had originated in the left hypochondrium and had moved to the periumbilical region. It was eased by lying still and was associated with several bouts of vomiting. He had no significant past medical history except for a history of abdominal pain one year previously following a blow on his abdomen. There was no history of trauma preceding the present admission.

On examination, he was pale, the heart rate was 80 per minute, and the blood pressure $130 / 80 \mathrm{mmHg}$. He was tender with guarding in the left hypochondrium and in the left flank. No masses were palpable. Haemoglobin was $10.5 \mathrm{~g} / \mathrm{dl}$, white cell count was $12.7 \times 10^{9} /$ litre, erythrocyte sedimentation rate was 3 $\mathrm{mm} / \mathrm{hr}$ and blood electrolytes and urea were normal. $\mathrm{X}$-ray of his abdomen suggested the presence of a soft tissue mass in the left hypochondrium.

Over the succeeding hour, he developed a tachycardia and rebound in his upper abdomen. At laparotomy, approximately 1.5 litres of free blood was found in the peritoneal cavity, and his spleen, which contained a large ruptured cyst, was bleeding briskly. The spleen, which was adherent to the diaphragm, was mobilized and routine splenectomy was performed. He made an uneventful recovery and was well when discharged on the tenth postoperative day.

The spleen weighed $240 \mathrm{~g}$ and contained an $11 \times 7$ $\mathrm{cm}$ cyst which showed trabeculation of the inner surface. Pathologically, it was a typical epithelial cyst

\footnotetext{
*Present address: Belfast City Hospital, Lisburn Road, Belfast, N.
}

of the spleen, and microscopically, the wall was lined with mature, well-differentiated squamous epithelium without skin adnexae.

\section{Discussion}

Epithelial cysts of the spleen are very rare, accounting for $10 \%$ of all non-parasitic cysts of the spleen (Bostick and Lucia, 1949), usually occurring in children or young adults and possibly arising from cell rests (Fowler, 1953). Their classification and pathogenesis have been extensively studied by Fowler in his classical papers of 1940 and 1953.

The most common mode of presentation is hypochondrial or epigastric pain frequently described as a dragging sensation. Usually these patients have splenomegaly or a mass in the left hypochondrium and various investigations including barium studies and ultrasound may be required to elucidate the diagnosis (Talerman and Hart, 1970). We report this case of spontaneous rupture of an epithelial cyst of the spleen presenting as an abdominal emergency as a most unusual presentation of a rare condition. We have found no other report of such a presentation in the English literature.

\section{Acknowledgments}

We wish to thank Mr J. G. W. Matthews, M.Ch., F.R.C.S. for permission to report a patient under his care, and Miss Anne Spence for typing the manuscript.

\section{References}

Bostick, W.L. \& LUCIA, S.P. (1949) Non-parasitic, non-cancerous tumours of the spleen. Archives of Pathology, 47, 215.

FOWLER, R.H. (1940) Cystic tumours of the spleen. International Abstracts of Surgery, 70, 213.

FOWLER, R.H. (1953) Non-parasitic benign cystic tumours of the spleen. International Abstracts of Surgery, 96, 209.

TALERMAN, A. \& HART, S. (1970) Epithelial cysts of the spleen. British Journal of Surgery, 57, 201.

(Accepted 21 April 1982) 